\title{
Immersive Experiences: The Future of Live Music and VR
}

\author{
Jeffrey Apruzzese \\ Drexel University \\ This paper was presented at the 2019 International Summit of the \\ Music \& Entertainment Industry Educators Association \\ March 21-23, 2019
}

https://doi.org/10.25101/19.24

\section{Abstract}

History has shown time and time again that technology can provide the opportunity to open up new vistas for fan experiences in the music and entertainment industries. While technology has disrupted many traditional music business models (e.g., pirating and illegal downloads on physical sales), it has opened many new business models (e.g., non-interactive and interactive streaming like Pandora and Spotify), as well as opening up limitless possibilities which are poised to be the new standards of fans' experience (e.g., hologram concerts and virtual reality experiences). With so much focus on fan experience and advances in new technologies, it seems that virtual concerts (e.g., Abba's Hologram tour, and Tupac Shakur's hologram at Coachella) are becoming increasingly popular and are poised to be a new standard in the concert experience, with the focus on experience, being the underlying driver of this technology.

As we can see from the high resell price on the secondary market where a front-row concert ticket, priced flat at $\$ 125$, could be selling for five to six times that on the secondary market, ticket prices are still priced staggeringly low, and a lot of fans are still unable to purchase tickets to see their favorite artists. With the equilibrium being off balance and there still being a vast demand for the concert-going experience, this provides unique opportunities to find alternative solutions to bring the concert-going experience to the consumer and explore other ways of monetization for the concert promoter. This paper examines the current and future landscape of live music and VR and details what potential licensing issues exist. It also provides an overview of the leading purveyors in VR live music integration and details what incentives exist for record labels, artists, the concert industry, and fans with VR and emerging technology platforms.

Keywords: live music, virtual reality, holograms, Live Nation, AEG, concerts, NextVR, Melody VR, Oculus
Jeff Apruzzese has over a decade of experience in the music industry and is a graduate of Berklee College of Music. Upon receiving his diploma, he became the bassist of Passion Pit (signed to Columbia Records) and was a member of the band for eight years. During his time in Passion Pit, he toured the world extensively, performed at some of the largest festivals (Lollapalooza, Coachella, Summer Sonic, Austin City Limits, Glastonbury, Made in America), and played on some of the highest profile late night shows (Saturday Night Live, David Letterman, Jimmy Kimmel). Apruzzese also has experience in PR and marketing and spent time working in New York City at the boutique agency Girlie Action Media with such clients as Surfer Blood, Kate Pearson (B-52's), Holy Ghost!, Mitski, Hop Along, Palehound, and many more. Jeff returned to Berklee College of Music in 2015 to help establish the Berklee Popular Music Institute (BPMI), which provides students with experiential learning in live music and performance. Under his guidance, BPMI booked major festivals including Lollapalooza, Outside Lands, Osheaga, Essence, Governors Ball, Chicago Open Air, and Music Midtown. Career highlights for Jeff include selling out the iconic Madison Square Garden in New York on February 2013 during a blizzard and having the Passion Pit record Gossamer debut at \#4 on the Billboard 200 chart.

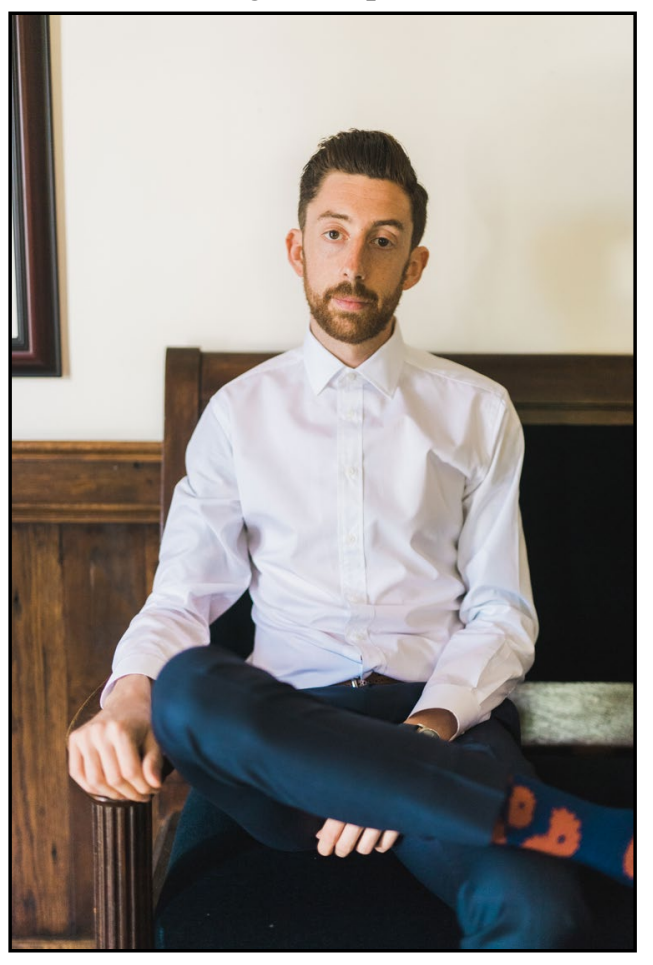




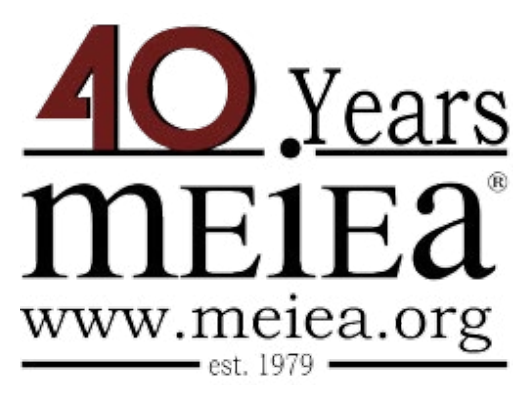

\section{PROCEEDINGS OF THE \\ 2019 INTERNATIONAL SUMMIT \\ OF THE \\ MUSIC \& ENTERTAINMENT \\ INDUSTRY EDUCATORS \\ ASSOCIATION}

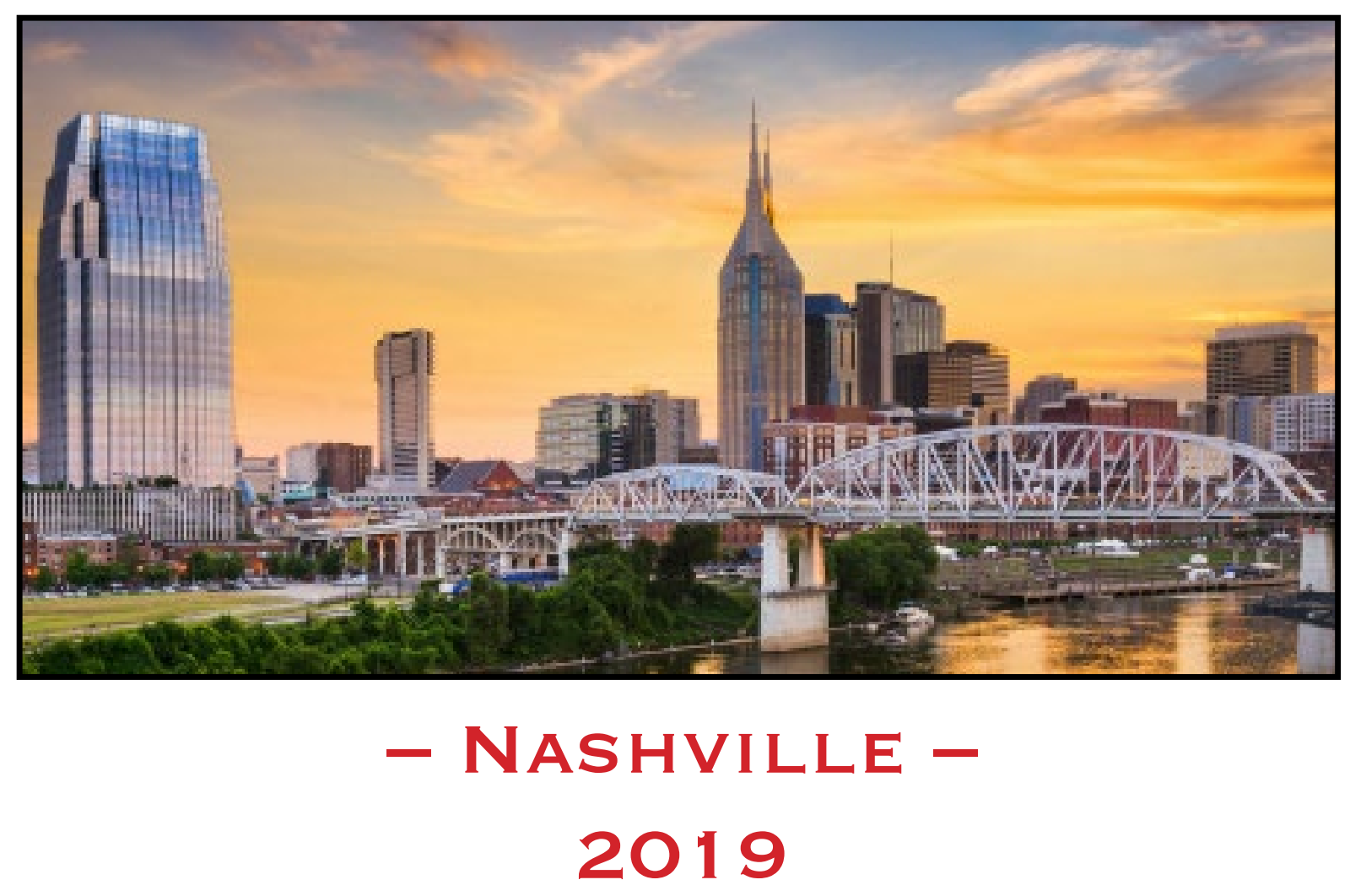

March 21 - 23, $2019 \cdot$ Belmont University - Nashville 